
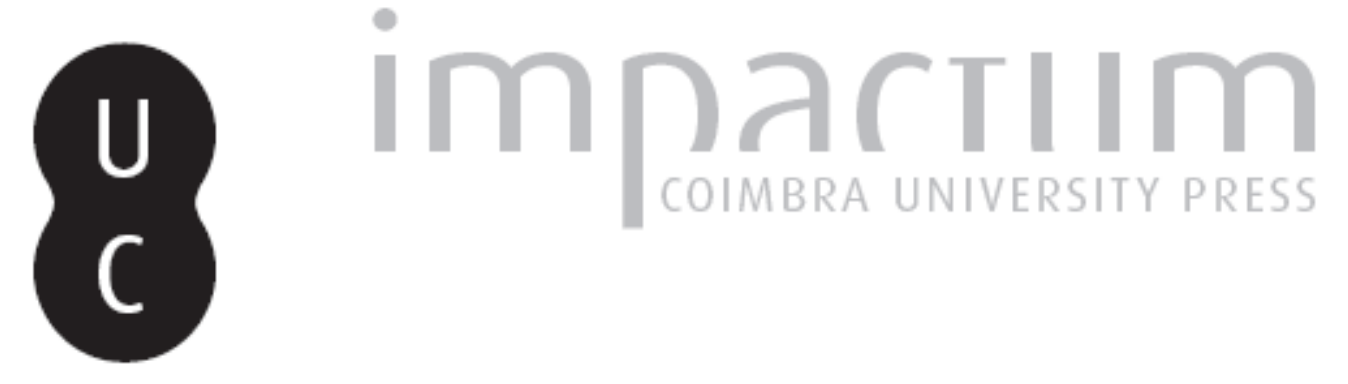

\title{
As reformas monetárias e o euro
}

\section{Autor(es): $\quad$ Andrade, João Sousa}

Publicado por: Imprensa da Universidade de Coimbra

URL persistente:

URI:http://hdl.handle.net/10316.2/43511

DOI:

DOI:https://doi.org/10.14195/2183-203X_45_5

Accessed : $\quad$ 26-Apr-2023 05:53:47

A navegação consulta e descarregamento dos títulos inseridos nas Bibliotecas Digitais UC Digitalis, UC Pombalina e UC Impactum, pressupõem a aceitação plena e sem reservas dos Termos e Condições de Uso destas Bibliotecas Digitais, disponíveis em https://digitalis.uc.pt/pt-pt/termos.

Conforme exposto nos referidos Termos e Condições de Uso, o descarregamento de títulos de acesso restrito requer uma licença válida de autorização devendo o utilizador aceder ao(s) documento(s) a partir de um endereço de IP da instituição detentora da supramencionada licença.

Ao utilizador é apenas permitido o descarregamento para uso pessoal, pelo que o emprego do(s) título(s) descarregado(s) para outro fim, designadamente comercial, carece de autorização do respetivo autor ou editor da obra.

Na medida em que todas as obras da UC Digitalis se encontram protegidas pelo Código do Direito de Autor e Direitos Conexos e demais legislação aplicável, toda a cópia, parcial ou total, deste documento, nos casos em que é legalmente admitida, deverá conter ou fazer-se acompanhar por este aviso. 


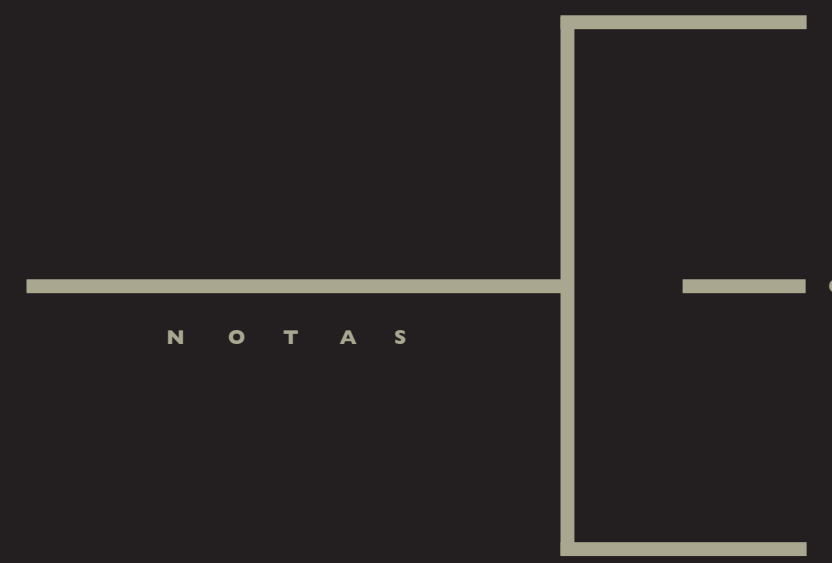

Helder Sebastião / António Portugal Duarte / Gabriel Guerreiro Where is the Information on USD/Bitcoin Hourly Prices?

ANA Fontoura GOUVEIA The Political Economy of Pension Systems with Low-Skilled Labor Mobility:A Cross-Country Analysis

Manuela Magalhães / Ana Paula Africano Panel Analysis of the FDI Impact on International Trade Revisited

Teresa Garcia / Paulo Vieira

O Mercado de Crédito Especializado ao Consumo em Portugal

JoÃo SOUSA ANDRADE As Reformas Monetárias e o Euro 


\title{
As Reformas Monetárias e o EURO1 João Sousa Andrade
}

Received for publication: September 21, 2017 Revision accepted for publication: November 10, 2017

\begin{abstract}
The creation of the Euro is discussed in this text in the context of the monetary reforms historically proposed by economists. Our reflection is made in terms of monetary orders based on commodities, the consequences of the legal tender and not convertible money, and includes the proposals for the free money. The way the money supply is created, generating its own demand, is essential to understanding the new monetary order arising from the Euro. The 100 percent reserves reform, the Mervyn King's proposal, and the extension of the function of lender of last resort are referred. We conclude by drawing attention to the need of an increased integration that leads to a more stable and credible Euro area, as well as to greater protection against financial shocks for Portugal after all.

Keywords: Euro; monetary reforms; money supply; and monetary stabilization.
\end{abstract}

JEL Classification: E42; E5 1; E58; E60.

${ }^{1}$ Este texto foi extraído da oração de sapiência proferida na abertura solene do ano escolar da Universidade de Coimbra, no dia 20 de Setembro de 2017. 
Esta intervenção visa enquadrar a reforma monetária que levou à criação do Euro, no processo de integração europeu, no contexto das reformas monetárias propostas para a organização das ordens monetárias. O tema central acaba assim por ser a moeda, bem que representa a forma mais geral dos direitos de propriedade privada e da qual o senso comum se mantém afastado da sua compreensão conceptual (Menger, 2012, von Mises, 1953, e Chaîneau, 1993, 2013). A moeda deve o seu valor à aceitabilidade generalizada, à possibilidade de troca generalizada e à sua disponibilidade temporal e espacial, não ao valor do papel que a representa, porque esse nem para tirar notas pessoais é útil. Porque assim é, as formas monetárias sem valor intrínseco correspondem a organizações sociais evoluídas.

O desenvolvimento do capitalismo exigiu a existência de "ordens monetárias" estáveis. Não teve o poder político a confiança dos indivíduos quanto à criação de uma moeda da sua exclusiva responsabilidade devido à instabilidade do seu valor. $\mathrm{O}$ poder político, com a sua necessidade permanente de receitas, destruía o valor da moeda. Lembremos a frase de Benjamin Franklin, que nada é mais certo que a morte e os impostos. Não conseguindo impostos o governo emitia moeda para se financiar, assim, a criação de moeda foi atribuída, muitas vezes, a agentes privados que compensavam adequadamente os cofres do Estado pela concessão de tal privilégio. De qualquer forma, a desconfiança na moeda não era eliminada e por isso os padrões metálicos dominaram durante muito tempo.

\section{Padróes de Bens físicos}

Foram várias as razões que levaram os metais preciosos a serem os escolhidos para representarem unidades monetárias. Ainda hoje temos saudosistas de um padrão-ouro, unidades monetárias representando um dado peso de ouro. No passado a sua importância foi tal, que a nossa velha moeda, o Escudo, apenas abandonou a designação de "Escudo-Ouro" após a reforma de 1975.

A subida do preço do petróleo nos anos setenta do século passado deu ânimo aos proponentes de um padrão-mercadorias. Os próprios EUA simpatizaram com a ideia, face aos disparar dos preços do petróleo. Seria uma forma de se protegerem da transferência de riqueza para os países da OPEC. E de resto, não eram conhecidas experiências deste tipo nos E.U.A.? Um "padrão-tabaco" funcionou durante dois séculos no Estado da Virgínia e um século e meio no Maryland (Walton e Rockoff, 2013, e Staples e Shaw, 2013).

A grande vantagem de um padrão-mercadoria reside no facto de a criação de moeda estar aparentemente subtraída ao poder discricionários dos governos. Uma das suas desvantagens reside na sua falta de elasticidade: o stock das mercadorias padrão não tem relação com as necessidades da economia. A desestabilização pela inflação e deflação são a consequência da ausência de elasticidade. Por outro lado, o seu fundamento não elimina o abuso dos créditos aos governos com a consequente desconfiança que acaba por recair sobre a moeda. 


\section{Moeda de Gurso Forçado}

As ordens monetárias atuais, no sentido que lhe deu Robert Mundell, caracterizam-se pela moeda ter "curso legal" e "curso forçado". No seu espaço político de circulação é obrigatória a sua aceitação em pagamentos e não são convertíveis em quaisquer bens que assumam o papel de garante oficial do seu valor. Em suma, o comerciante não pode recusar que lhe paguem nessa moeda e o assalariado não pode recusar que lhe paguem o salário nessa mesma moeda.

Símbolo do poder centralizador do príncipe a existência de moeda teve de afrontar as tendências desagregadoras nacionalistas. Uma bandeira, uma moeda. Não temos de ir mais longe que lembrar o Zarco, para a Madeira, e o Açor, para os Açores, no pós-revolução do 25 de abril.

No passado, perante a anarquia da circulação de várias moedas, o capitalismo desenvolveu-se caminhando para o monopólio público da criação e emissão de moeda. As finanças públicas deficitárias empurravam a "moeda pública" para a perda de valor e a instabilidade. O ponto culminante das reformas para a adequada emissão de moeda situou-se em Inglaterra, entre 1820 e 1845 e refletiu-se na polémica entre a Currency School e a Banking School (Goodhart e Jensen, 2015, e Dorofteia, 2013) precursoras das principais correntes do pensamento monetário. Uma corrente menor fez também aí a sua aparição: a Free Banking School (Schwartz, 2008), que defendia a liberdade de emissão de moeda. Esta tendência reapareceu em contraposição à proposta animada por Jacques Delors de uma moeda única para a Europa (Delors, 1992).

\section{O Mundo Idílico do FreE Money}

A posição dos pais da economia, Adam Smith, David Ricardo, Leo Walras e Jean-Baptiste Say, era clara: "o poder público porta-se mal com a emissão de moeda, mas entregá-la a privados é um risco excessivo" (Andrade, 1987). Os economistas liberais da Free Money (Yeager, 1983a, 1983b) contrapõem que os princípios do bem-estar dos consumidores se devem aplicar também à moeda e por isso a concorrência deve existir quanto à produção de moeda. São vários os problemas que de imediato identificamos:

1. o passado revelou que os sistemas com concorrência de moedas foram desastrosos para a estabilidade monetária;

2. os princípios da economia do bem-estar não podem ser aplicados à escolha dos consumidores perante a concorrência das moedas porque a utilidade de posse de uma dada moeda não é independente da utilidade que os restantes agentes retiram dessa mesma posse;

3. os atuais sistemas monetários são mistos: a par de uma moeda pública, as notas e moedas de trocos, temos moeda escritural, emitida por bancos de depósitos, que hoje movimentamos sobretudo através de cartões eletrónicos. Esta "moeda privada", sujeita à convertibilidade a $100 \%$ em moeda pública, em notas, nunca protegeu os seus possuidores da perda de valor de compra em situações de inflação; como 
podemos então provar que uma moeda privada sem necessidade de convertibilidade o iria fazer?

4. a concorrência entre "produtores" dessas moedas vai levar ao monopólio: à medida que o espaço de circulação de uma moeda aumenta reduzem-se os custos e aumentam os benefícios da sua utilização. No final apenas um produtor existirá, pelo que a própria reforma se auto-elimina.

\subsection{Gongorrência de Moedas Nagionais na Europa}

O "Manifesto do Dia de Todos-os-Santos" (Fratianni et al., 1975) propunha para a (atual) União Europeia (UE) a emissão de uma nova moeda a "Europa" com poder de compra constante que circularia em concorrência com as moedas nacionais. Seria assim respeitado o princípio da livre escolha dos consumidores. A presença desta nova moeda levaria a que as moedas nacionais fossem pouco a pouco abandonadas restando finalmente a nova moeda. Sobretudo em países de elevada inflação seria rápido o período de transição e o processo seria, por isso, desestabilizador.

Em 1989, o Chancellor of the Exchequer inglês, Nigel Lawson, propôs que as moedas nacionais tivessem curso legal em toda a área da UE originando-se assim um processo de concorrência de moedas levando a que os consumidores pudessem em plena liberdade escolher a moeda que desejassem (Wood, 1992). Em 1990 o sucessor de Nigel Lawson, o futuro primeiro-ministro John Major juntou a presença de uma nova moeda que existiria em paralelo com as moedas nacionais, o "ECU-forte" ou "Hard-Ecu" (Holmes, 2001). Ambos os projetos foram recusados. Mas convém lembrar que John Major, declararia numa entrevista que estava convencido que num futuro não muito distante a Libra viria a ser tão forte como o Marco alemão (Holmes, 2001, p. 32).

A ideia de concorrência das moedas não andou assim longe dos europeus (Issing, 1999).

\section{Como se Produz Moeda?}

O conceito de criação de moeda não é dos de mais fácil compreensão em economia. À moeda, como a qualquer outro bem, podemos aplicar o conceito de procura e oferta. Os indivíduos procuram moeda tendo em conta a sua riqueza (ou o seu rendimento), o consumo pretendido, a inflação e o seu custo de oportunidade em termos da taxa de juro. Mas quem a oferece? Os bancos. Os bancos através das suas operações de crédito colocam na economia (não bancária) as notas e os seus depósitos: moeda pública e privada.

A oferta de moeda resulta do confronto de interesses dos bancos e, sobretudo, das unidades de produção. Estas pretendem crédito dos bancos, porque desejam meios de financiamento. A essa procura de financiamento corresponde uma oferta de crédito por parte dos bancos. A oferta de moeda vai criar uma quantidade de meios de pagamento a favor das unidades de produção, que de imediato os usarão. As unidades de produção não pretendem moeda para acumular, mas antes para fazer pagamentos, para investir, 
pagar bens que compram e ainda salários. Essa moeda estará em circulação a partir do momento que o crédito foi concedido. Ela vai ser possuída por alguém que afinal nada teve a ver com o seu processo de criação. Oferta e procura de moeda são conceptualmente diferentes.

Vejamos o que se passa de diferente com um qualquer mercado de um outro bem. Se a oferta de um bem for superior à sua procura, para um preço tomado como caracterizando o mercado, é natural que no período seguinte a oferta seja inferior. Aliando este comportamento ao facto de a produção ser feita porque se antecipa uma vontade de comprar porque parte de outros agentes, podemos dizer que a procura, ou o que se espera que ela seja, precede a oferta. Associado ao fenómeno da oferta encontramos o da procura antecipada. Ou, de outra forma, a procura constrange a oferta. Veja-se o que acontece com a moeda. A oferta de moeda precede a procura. Como insistia Chaîneau (1995, 2000), a oferta de moeda leva à criação de moeda que acaba por ser possuída pelos agentes da economia. Os agentes não têm outra alternativa que possuir essa quantidade criada. Não podemos conceber a existência de moeda sem um seu proprietário. Para além de a oferta preceder a procura de moeda, esta última não tem qualquer influência sobre a oferta de moeda. Os bancos não antecipam variações da procura de moeda para definirem a sua política de concessão de crédito às unidades de produção.

A relação que se estabelece entre procura e oferta leva a distinguir a moeda dos restantes bens. As diferenças são mesmo substanciais. De forma alguma podemos dizer que a moeda é mais um bem na economia. Temos de facto uma procura e uma oferta, mas elas são independentes. Por isso, é natural que tenhamos um valor da oferta de moeda inferior ou superior àquele outro valor da procura de moeda. Se tivermos uma diferença positiva, isso equivale a uma posição de sobre-liquidez de que resultará uma maior procura de bens e de ativos financeiros e portanto um aumento do valor nominal das vendas e uma redução da taxa de juro. Se bem que o equilíbrio ex post seja logicamente uma necessidade, isso não significa que o equilíbrio obtido corresponda necessariamente aos valores que foram antecipados pelos agentes possuidores de encaixes monetários.

O grande economista John Hicks contribuiu para uma grande confusão: ao considerar a moeda como mais um bem cuja característica distintiva residia na sua "liquidez". A especificidade da moeda era anulada e depressa a vulgata keynesiana passaria a falar do "mercado da moeda" em paralelo com os outros mercados - como se um mercado altamente profissional de créditos de curto prazo em que participam os bancos não existisse já nas economias, esse sim "o mercado monetário". A problemática do equilíbrio monetário era reduzida a mais um mercado e a distinção fundamental lembrada por Patinkin (1965) entre o "individual experiment" e o "market experiment", que autores como Walters (1998) e Matthews e Peel (2004) e Laidler (1975, 2004), tão bem souberam identificar no estudo da inflação e que seria posteriormente representada econometricamente no sistema proposto por (Johansen, 1991, 1995) acabaria por ser ignorada. Essa incapacidade do keynesianismo vulgar leva ainda hoje à incapacidade de representação adequada do fenómeno da "liquidity trap" e à não identificação do problema da oferta de moeda no cerne desta situação. 


\section{A Oferta de Moeda no Gentro das Ordens Monetárias}

Como sugerimos atrás, a oferta de moeda está no cerne das ordens monetárias.

A Inglaterra não suspendeu o padrão-ouro no seguimento da primeira GM, mas de 1916 a 1919 a cotação da Libra era mantida graças ao crédito de J. P. Morgan and Co., de Nova Iorque. O Banco de Inglaterra não tinha condições para assegurar a convertibilidade da Libra. O padrão-ouro foi suspenso quando a casa americana recusou o prolongamento do contrato (Bernanke e James, 1991, Eichengreen, 2008, e Duarte, 2015). Anos mais tarde, Montagu Norman, Governador do Banco de Inglaterra, faz uma proposta típica de um império que havia deixado de o ser, reclama a criação de uma rede de bancos centrais independentes dos governos, que cooperariam entre si, dirigidos de forma discreta pelo Banco de sua Majestade, obviamente. A "conta" seria paga pela Comissão Financeira da Sociedade das Nações (Cain e Hopkins, 2016).

Quando em 1933 os EUA suspendem o padrão-ouro, desvalorizando o dólar, alguns países mantiveram-se ligados ao ouro. Não foram as conferências que resolveram o relacionamento dos dois blocos: o "bloco-dólar" e o "bloco-ouro". A deflação no "bloco-ouro" resolveu o problema. As moedas ligadas ao dólar desvalorizavam-se face às moedas referidas ao ouro, o que provocou nestas últimas economias a deflação com a consequente queda da produção e aumento do desemprego.

Na primeira metade dos anos 80 do século passado, a Inglaterra opôs-se à transição para uma moeda única na Europa. O que é o mesmo, recusou perder de vez o papel imperialista que teve na história. A perda da Libra, como moeda internacional, corresponde ao caminho sem retrocesso iniciado desde o início do século passado. Mas não se fecha uma história imperialista de vontade própria. Uma das propostas que chegou a ser invocada, aproveitando argumentos liberais, propunha que em vez da criação artificial de uma moeda se admitisse a livre escolha de moedas nas transações, o que levaria ao início de um período de concorrência entre moedas, que permitiria que os agentes escolhessem a melhor moeda. De uma forma populista quase se dizia, "sim à moeda escolhida pelos consumidores", "não à moeda escolhida por Bruxelas". A inspiração Hayekiana da posição era óbvia. Mas uma reforma deste tipo envolve custos elevadíssimos, económicos e políticos. Os ingleses estavam seguros que ela não poderia ser experimentada. A sua não exequibilidade seria a sua principal característica, mas travaria o processo de integração monetária na Europa. Se os agentes económicos pudessem escolher em liberdade uma moeda, com certeza escolheriam a que maiores garantias lhes desse de manutenção do poder de compra, na altura: o florim e o marco. E até a escolha do florim era já uma escolha do marco (Holmes, 2001, p. 90). Afinal a escolha do mercado não se afastaria da "escolha de Bruxelas".

Ainda a Segunda Grande Guerra não havia terminado e já se preparava a reforma para uma nova ordem monetária que iria suceder ao "império do esterlino". As regras dos acordos de Bretton-Woods eram a confirmação ao nível económico da nova potência imperialista: os EUA. Resumindo, o dólar norte-americano passava a ser tão bom como o ouro, mas apenas na primeira metade dos anos sessenta esta moeda ultrapassou a Libra nos pagamentos internacionais. A emissão de moeda por parte dos EUA para pagar os seus desequilíbrios externos e um sistema de câmbios praticamente fixos ditaram a inflação mundial crescente, a partir sobretudo da segunda metade dos anos sessenta. 
A não independência dos bancos centrais do respetivo poder político levava a políticas orçamentais expansionistas independentemente dos ciclos económicos. A dívida pública podia ser financiada pelos bancos centrais com taxas de juro muito baixas. Desde que a oferta de moeda não levasse as economias nacionais a taxas de inflação superiores à dos EUA, o pivot desta ordem, o sistema era estável. A inflação, entretanto, reduzia o valor real da dívida. Um mundo perfeito para a irresponsabilidade a nível orçamental. Inflação crescente nos EUA e inflações crescentes e divergentes nos restantes países levaram ao fim da ordem de Bretton-Woods no início dos setenta. Como sabemos, foi neste contexto de forte e crescente instabilidade monetária que o projeto europeu de estabilidade cambial e posterior união monetária surgiram.

\subsection{Haverá Regras Ótimas para a Emissão de Moeda?}

Os economistas conhecem através dos seus modelos, teóricos e empíricos, os custos associados à inflação e sobretudo à inflação não esperada. Então têm respostas precisas para a quantidade de moeda? Não, não têm! A primeira posição para um ótimo de bem-estar veio de uma representação demasiado abstrata de Friedman (1956) em que a oferta de moeda deveria em equilíbrio conduzir a economia a uma taxa de deflação (de decréscimo dos preços) idêntica à taxa de juro de equilíbrio. Esta situação provocaria a igualdade de taxas de rentabilidade dos ativos possuídos pelos indivíduos. Esta ideia é por vezes suportada por aqueles que argumentam que a produção de moeda por um banco central privado levaria este a reduzir a quantidade de moeda em circulação de forma a aumentar o poder de compra das unidades monetárias, afinal da sua produção. Ideia esta baseada num conceito de senhoriagem que não atende à forma como a moeda é criada e posta em circulação: pelo crédito bancário. A análise mais corrente sobre a taxa a que a moeda deve ser produzida, propõe uma leitura em termos do comportamento dos indivíduos quanto à moeda detida, quanto à procura de moeda. E neste caso, se o objetivo for a maximização dos lucros do banco central que a produz, então as taxas de inflação geradas serão insuportáveis: sempre acima dos 100\% (Bofinger, 2006).

Estes argumentos reforçam a posição dos autores clássicos: os governos podem ser irresponsáveis mas apesar disso é preferível que a moeda seja produzida por um banco público e que procuremos definir as regras da emissão.

\subsection{A Lei de Peel (1844) e o Seu Aprofundamento}

A Lei d e Peel (1844) é um marco importante no estabelecimento definitivo da produção de moeda de forma pública. E as propostas que se seguiram ao crescimento descontrolado da inflação na segunda metade do século passado, procuravam formas de controlo da quantidade de moeda. Ao mesmo tempo ficou claro para os economistas que a estabilidade monetária desejada para a economia é um fenómeno de longo prazo e que a prática dos governos os insere num contexto de curto prazo. Para alguns, isto representa uma incompatibilidade que apenas pode ser resolvida com a independência dos bancos centrais. 
Embora não seja função dos bancos centrais lutar contra injustiças sociais, não nos esqueçamos do que representam elevadas taxas de inflação. Reavivemos a nossa memória. Em Portugal a taxa de inflação atingiu 28,5\% em 1984, um máximo histórico. Desde 1978 que as taxas estavam na casa dos 20\% . 500 escudos no início de 1978 valiam apenas 127 escudos em 1984. As taxas de juro para créditos a mais de 1 ano andavam por valores superiores a 32,5\%. Quem tivesse pedido 100 escudos no início de um dado ano, ao fim de 5 anos devia mais de 4 vezes aquele valor. O USD cuja cotação histórica eram os 28 escudos e 50 centavos valia em 1984170 escudos. Quem tinha poder reivindicativo podia corrigir esta desvalorização nominal, os que não tinham, viam os seus rendimentos cair. Errar em 50\% a previsão da taxa de inflação significava um erro absoluto de $15 \%$ no seu valor, fatal para empresas e, ou, trabalhadores. Uma ordem monetária que não respeita a estabilidade monetária contribui para uma sociedade de conflitos e de desespero de muitos. A única solução será continuar a aumentar os défices públicos, continuar assim a aumentar a inflação? Até onde? Esta é naturalmente uma falsa solução.

E afinal o problema não reside nas finanças públicas e no oportunismo de governos que pretendem fazer despesas sem que para tal tenham as receitas correspondentes, no curto ou longo prazos? Uma ordem monetária dominada pelo poder político é uma ameaça à estabilidade da economia e ao bem-estar.

Símbolo do poder, da soberania, sobre um território, a moeda sofreu a erosão que essa mesma soberania foi sofrendo com a integração económica, social e política. O controlo de uma moeda própria continua a ser crucial à irresponsabilidade orçamental fazendo com que consumidores, em geral, e trabalhadores em particular, no ativo ou reformados, cubram esses custos.

\section{Outras Reformas Monetárias}

\subsection{Uma Reforma Liberal Radical: Reservas Bancárias a 100\%}

A Islândia foi exemplar na responsabilização criminal de responsáveis bancários pela crise bancária de 2008 no país. Na reavaliação das responsabilidades de supervisão por parte do seu banco central a Reforma dos $100 \%$ foi reavivada com uma proposta avançada no parlamento islandês (Sigurjónsson, 2015).

Ao Crash bolsista de 1929 sucederam-se, nos EUA, as crises bancárias de 1930 e 1931. Em 1933 o poder legislativo americano admite nacionalizar os bancos e em 1934 surge uma proposta para a criação de um único banco com o monopólio do crédito para os EUA. Dois economistas liberais vão sobressair no diagnóstico da situação de crise: Irving Fisher, (Fisher, 2009), com a sua insistência no sobre-endividamento, e Milton Friedman, que se foca na instabilidade da oferta de moeda criada pelos bancos (Friedman, 1960, 1967, e Benes e Kumhof, 2012). O projeto de "reservas a 100\%", ou seja, os bancos têm de deter em cofre um montante de notas idêntico aos depósitos que aceitam, elaborado por outro economista liberal, Henry Simons, circula no meio académico da Universidade de Chicago. Existe opinião favorável a tal reforma na administração Roosevelt. Nessa altura Irving Fisher será a figura mais conhecida do plano e, posteriormente, será Milton 
Friedman. O objetivo: separar a função de crédito da criação de moeda e atribuir o controlo da quantidade de moeda que circula na economia ao governo! Pretendiam assim, preservar o capitalismo e evitar a nacionalização da banca! Se em 1939200 economistas assinaram o manifesto da reforma, em 1941 já eram 400!

O poder dos banqueiros obviamente que não permitiu que os economistas liberais levassem a reforma avante e em consequência apenas o Glass-Steagall Act (1933) será aprovado. Nesta lei, que fará história nos sistemas bancários e monetários mundiais, é estabelecida a separação entre a banca comercial e a banca de investimento. Sendo esta última muito exigente em requisitos de capital e, por isso, tradicionalmente menos rentável, a pressão foi enorme para que o regime imposto por aquela Lei fosse abandonado. Em 1999 o Gramm-Leach-Bliley Act anulará a separação entre banca comercial e de investimento (Akhigbe e Whyte, 2004). Para muitos economistas tal não separação foi em parte responsável pela crise de 2008 e no conjunto das propostas para a reorganização bancária a separação voltou a ser reclamada. A voz com maior autoridade é a de Paul Volcker, o presidente do FED que se notabilizou no início dos anos oitenta pelo controlo da inflação, numa altura em que esta parecia estar descontrolada (Cassidy, 2010).

Seguramente a Reforma dos 100\% terá, agora na Islândia, o mesmo destino que teve nos trinta do século passado nos EUA.

Para além da proposta apoiada por Paul Volcker que outras propostas de ordens monetárias surgiram no rescaldo da crise financeira de 2008?

\subsection{A Reforma de Mervyn King}

Este professor de economia e ex-governador do Banco de Inglaterra (King, 2016) critica o desenvolvimento do conceito de incerteza traduzida em risco probabilizável e propõe que se tenha em conta o que ele designa por "incerteza radical", re-introduzindo a ideia de incerta não-probabilizável keynesiana. Neste contexto propõe, em 2016, que os bancos centrais se constituam como "casa de penhores para todas as situações" (pawnbroker for all seasons). Cabe aos bancos centrais conceder crédito em qualquer situação aos bancos aceitando como penhora os seus ativos com base em desconto (haircut) a avaliar pelos bancos centrais. No fundo propõe a generalização do princípio enunciado por Walter Bagehot, em 1873, de "prestamista em última instância" (Lender of Last Resort, LLR) sem qualquer limite para além do valor dos ativos dos bancos socorridos. A reforma é em geral referida pela importância do proponente e não pela sua relevância. Como comentou (Krugman, 2016), como conciliar esta reforma com o princípio da "incerteza radical"? E que de novo, relativamente às regras hoje exigidas para o capital dos bancos, traz esta ideia? Esta proposta de Mervyn King é apenas uma alínea de uma reforma que inclui a eliminação do Euro com a reintrodução de moedas nacionais em regime de câmbios flexíveis. Nada de novo do outro lado do Canal. 


\subsection{O Alargamento da Função de "Prestamista em Última Instância" (LLR)}

Justifica-se que falemos desta função porque ela tem sido avançada sem qualquer referência à ideia original de Bagehot (1873) e Jeffers (2010). A ideia é simples: quando os governos não conseguem financiar-se a taxas razoáveis o banco central deverá comprar esses títulos. O banco central seria assim o "último credor". É óbvio que tal comportamento eliminaria qualquer independência dos bancos centrais colocando-os como agências do Tesouro. A função de LLR faz hoje parte dos instrumentos de estabilização usados pelos bancos centrais. A ideia de Bagehot era de concessão de crédito a bancos solváveis em situação de crise de liquidez. Não se trata nem de emprestar a governos nem a bancos com falência à vista.

O FED alargou esta função a empréstimos a empresas não-bancárias com sucesso evidente na recente crise financeira. O Banco Central Europeu, quanto ao alargamento desta função, defrontou a frouxa integração política da UEM e apenas em 2106 começou a fazer este tipo de operações para introduzir diretamente liquidez na economia e não apenas pela via indireta do crédito a bancos.

\section{Gonclusão}

Se os problemas identificados como traduzindo uma "preferência absoluta pela liquidez" caracterizassem a atual situação, poderíamos pensar em Sílvio Gesell e na sua reforma que levava a validar as notas através de selos que corresponderiam a uma perda de valor da moeda equivalente a 5\% (Gesell, 1958). Ou até pensar em Szilard (1949), o físico atómico, com a sua moeda de cor vermelha para ser usada em despesas e de cor verde para ser entesourada, mas esta estaria sujeita a desvalorização.

No mundo bipolar da Segunda Grande Guerra até ao início dos noventa, o bloco ocidental viveu, após a queda de Bretton-Woods, um período de forte instabilidade cambial. O Acordo do Plaza (1985) e o encontro de Paris (1987), (Taylor, 2015), se anularam conflitos cambiais centrados nas três moedas dominantes, o dólar, o marco e o iene, não levaram à desejada estabilidade. O Sistema Monetário Europeu (SME), estabelecido em março de 1979, veio trazer à Europa, lentamente, a tão desejada estabilidade cambial. O caminho não foi sem retrocessos. Em face da especulação acrescida a banda de flutuação das suas moedas passou dos 2,25\% (e 6\%) para os $15 \%$ em 1993. Os que já na altura anunciaram o fim do sistema, que afinal prosseguiu para a institucionalização do Euro, continuaram posteriormente a anunciar os vários fins do Euro. Como lembraram recentemente (Obstfeld e Taylor, 2017) o trilema clássico da política monetária enfatizava que a combinação de câmbios flexíveis com a mobilidade de capital permitia à política monetária preocupar-se com os objetivos nacionais. Fora desta análise estava, o que se revelaria de fundamental importância com a crise de 2009, a estabilidade financeira. Por si, a política monetária não é suficiente para a garantir e as pequenas economias estão muito mais sujeitas aos choques externos de natureza financeira. Neste mundo que abandonou a bipolaridade pertencer a uma zona monetária é um seguro contra esses choques externos. Não se conhecem, aliás, outras formas de proteção mais eficazes a esse risco. 
A análise económica não garante que as regras de natureza orçamental sejam a melhor forma de governação, mas é necessário que haja governação! As regras orçamentais são assim necessárias para impedir a contaminação da instabilidade na ausência de governação orçamental europeia. O "fiscal compact" é um passo nesse sentido onde sobressai o "semestre europeu" como um elemento importante para essa governação.

A União Bancária é, já hoje, uma realidade e o seu processo de consolidação é irreversível (Véron, 2013, e Howarth e Quaglia, 2014).

A política monetária do BCE com Mario Draghi foi inovadora nas medidas de política monetária não convencionais. Se algumas das políticas foram demasiado lentas na sua aplicação isso ficou a dever-se à ausência de quadro institucional que apenas uma mais intensa integração europeia permitiria. De igual forma, a exigência de "responsabilização" e "transparência" necessitam de quadros institucionais que apenas maior integração política possibilita.

O Euro é um elemento fulcral nesta União Monetária que se pretende um espaço de estabilidade financeira e monetária, essencial ao crescimento do emprego e do bem-estar. Mas a União Monetária exige orçamentos sustentáveis. Uma mais intensa integração política permitirá uma política orçamental que contribuirá para políticas orçamentais ativas, evitando regras que geram ineficiências macroeconómicas. Se a resposta à crise grega em 2009 foi tardia, o mesmo não aconteceu posteriormente com a Irlanda e Portugal. A atitude do BCE evitou o alastramento da crise financeira a países como a Itália e a Espanha. A cobertura do risco de choques financeiros externos de que a nossa economia beneficia pela sua pertença à UEM exige a contribuição portuguesa para uma mais intensa integração política.

Em suma, as reformas monetárias propostas vão desde os padrões metálicos à moeda exclusivamente privada, passando pela imposição de reservas bancárias a 100\%, mas também por outras formas menos radicais como o alargamento da função de prestamista em última instância. A reforma europeia de uma moeda única para um conjunto de países respeitando finanças públicas sustentáveis insere-se numa conceção clássica do papel da moeda na economia.

O Euro constitui o elemento essencial da reforma monetária europeia. A integração monetária como foi desenhada para a União Económica e Monetária (UEM) criou uma área de estabilidade monetária essencial ao crescimento do emprego e do bem-estar dos cidadãos europeus. Esta área é fundamental para pequenos países como Portugal para ficarem protegidos de choques financeiros e monetários externos. Mas a UEM para responder aos seus objetivos tem de assentar na sustentabilidade das finanças públicas. Sem uma integração política mais profunda a UEM tem de ser gerida por regras que levam a situações sub-ótimas pela sua própria natureza de regras. A União Bancária e o Euro constituem pilares da estabilidade bancária e monetária. Caminhar no sentido de maior integração a nível político é fortalecer essa estabilidade. 


\section{REFERÊNGIAS BIBLIOGRÁFIGAS}

Akhigbe, A.; Whyte, A.M. (2004) The Gramm-Leach-Bliley Act of 1999: Risk implications for the financial services industry, Fournal of Financial Research, 27 (3), 435-46.

Andrade, J.S. (1987) L'Etat, le Marché et la Monnaie, Lisboa, Imprensa Nacional-Casa da Moeda.

Bagehot, W. (1873) Lombard Street: A Description of the Money Market, New York, Scribner, Armstong.

Benes, J.; Kumhof, M., The Chicago Plan Revisited, Technical report, IMF, Working Paper, WP/12/2012.

Bernanke, B.; James, H. (1991) Financial Markets and Financial Crises, Chicago, University of Chicago Press.

Bofinger, P. (2006) Monetary Policy, Goals, Institutions, Strategies, and Instruments, Oxford, Oxford University Press.

Cain, P. J.; Hopkins, A.G. (2016) British Imperialism, 1688-2015 (3 ${ }^{\text {rd }}$. ed.), Abingdon, Routledge.

Cassidy, J. (2010) The Volcker rule Obama's economic adviser and his battles over the financial-reform bill, The New Yorker, July 26th.

Chaîneau, A. (1993) Qu'est-ce que la Monnaie?, Paris, Economica.

Chaîneau, A. (1995) Equilibre, Déséquilibre, Monnaie, Faculdade de Economia, Coimbra, GEMF Working paper.

Chaîneau, A. (2000) Mécanismes et Politique Monétaire, Paris, P.U.F.

Chaineau, A. (2013) La Monnaie et ses Singularités, Notas Económicas, 37, 23-32.

Delors, J. (1992) Le Nouveau Concert Européen, Paris, Editions Odile Jacob.

Dorofteia, I. (2013) The lessons of the currency school-banking school dispute for the present post-crisis economy, PROCEDIA, Economics and Finance, 6, 48-56.

Duarte, A.P. (2015) O Sistema Monetário Internacional: Uma Perspectiva Histórico-Económica, Coimbra, Almedina.

Eichengreen, B. J. (2008) Globalizing Capital: A History of the International Monetary System $\left(2^{\text {nd }}\right.$. ed.), Princeton, Princeton University Press.

Fisher, I. (2009 [1936]) 100\% Money and the Public Debt, Pakthongchai, Michael Schemmann ThaiSunset Publications.

Friedman, M. (1960) A Program for Monetary Stability, New York, Fordham University Press.

Friedman, M. (1967) The monetary theory and policy of Henry Simons, The Journal of Law and Economics, 10 (October), 1-13.

Friedman; M. (1956) The Quantity Theory of Money: A Restatement, Studies in the Quantity Theory of Money, Chicago, University of Chicago Press.

Gesell, S. (1958 [1916]) The Natural Economic Order, London, Peter Owen.

Goodhart, C.; Jensen, M. (2015) Currency School versus Banking School: An ongoing confrontation, Economic Thought, 4 (2), 20-31.

Holmes, M. (2001) European Integration: Scope and Limits, London, Palgrave.

Howarth, D.; Quaglia, L. (2014) The steep road to European banking union: Constructing the single resolution mechanism, Fournal of Common Market Studies, 52 (S1), 125-40.

Issing, O. (1999) Hayek: Currency competition and European monetary union, URL https://www.ecb. europa.eu/press/key/date/1999/html/sp990527.en.html.

Jeffers, E. (2010) The Lender of Last Resort Concept: from Bagehot to the Crisis of 2007, Revue de la Régulation, Capitalisme, Institutions, Pouvoirs, 8, Autumn. 
Johansen, S. (1991) Estimation and hypothesis testing of cointegration vectors in Gaussian vector autoregressive models, Econometrica, 59 (6), 1551-80.

Johansen, S. (1995) Likelihood-Based Inference in Cointegrated Vector Autoregressive Models, Oxford, Oxford University Press.

King, M. (2016) The End of Alchemy: Money, Banking and the Future of the Global Economy, London, W. W. Norton.

Krugman, P. (2016) Money: The brave new uncertainty of Mervyn King, New Fork Times, July, $14^{\text {th }}$.

Laidler, D. (1975) Essays on Money and Inflation, Manchester, Manchester University Press.

Laidler, D. (2004) Macroeconomics in Retrospect: The Selected Essays of David Laidler, Cheltenham, Edward Elgar.

Fratianni; M.; Basevi, G.; Giersch, H.; Korteweg, P.; O’Mahony, D.; Parkin, M.; Peeters, T.; Salin, P.; Thygesen, N. (1975) The all Saints' Day manifesto for European Monetary Union, The Economist, 1, 33-38.

Matthews, I.P.K.; Peel, D.A. (2004) Alan Walters and the Demand for Money: An empirical retrospective, in Minford, Patrick (Ed.), Money Matters, Essays in Honour of Alan Walters, Cheltenham, Edward Elgar, 148-68.

Menger, C. (2012) On the Origins of Money (1892), Auburn, Ludwig von Mises Institute.

Obstfeld, M.; Taylor, A.M. (2017) International Monetary Relations: Taking finance seriously, Fournal of Economic Perspectives, 31 (3), 3-28.

Patinkin, D. (1965) Money, Interest, and Prices (2 ${ }^{\text {nd }}$. ed.), New York, Harper and Row.

Schwartz, A.J. (2008) Banking school, currency school, free banking school, in Steven N. Durlauf, S.N.; Blume, L.E. (Eds.), The New Palgrave Dictionary of Economics, Basingstoke, Palgrave Macmillan.

Sigurjónsson, F. (2015) Monetary Reform, A Better Monetary System of Iceland (commissioned by the Prime Minister of Iceland), Reykjavik, Government of Iceland.

Staples, K.A.; Shaw, M.C. (2013) Clothing Through American History: The British Colonial Era, Santa Barbara, ABC-CLIO.

Szilard, L. (1949) Free market economy in a "constant flow" monetary system, URL https://library. ucsd.edu/dc/object/bb5086907h/\s \do6(1).pdf.

Taylor, J.B. (2015) A Rules-Based International Monetary System for the Future, Washington, Petersen Institute for International Economics.

Véron, N. (2013) A Realistic Bridge Towards European Banking Union, Bruegel Policy Contribution, 2013(09).

von Mises, L. (1953) The Theory of Money and Credit (1912), New Haven, Yale University Press.

Walters, Alan (1998) The Economics and Politics of Money, The Selected Essays of Alan Walters, Cheltenham, Edward Elgar.

Walton, G.M.; Rockoff, H. (2013) History of the American Economy, Mason, Cengage Learning.

Wood, G. (1992) An Introduction to Monetary Union, Basingstoke, Palgrave Macmillan.

Yeager, L.B. (1983a) Stable Money and Free Market Currencies, Cato Fournal, 3 (1), 305-26.

Yeager, L.B. (1983b) A Laissez-faire Approach to Monetary Stability, Fournal of Money, Credit and Banking, 15, 302-15. 